Bull. Mater. Sci., Vol. 8, No. 1, February 1986, pp. 53-60. (C) Printed in India.

\title{
Thermal expansion studies on As-Sb-Se glasses
}

\author{
A GIRIDHAR, SUDHA MAHADEVAN and A K SINGH \\ Materials Science Division, National Aeronautical Laboratory, Bangalore 560017, India \\ MS received 24 September 1985

\begin{abstract}
The results of measurement of thermal expansion coefficient from $50^{\circ} \mathrm{C}$ to the softening temperature on eight glass compositions of the As-Sb-Se system are presented. Measurements have been made on $(\mathrm{As}, \mathrm{Sb})_{40} \mathrm{Se}_{60}$ and $\mathrm{As}_{x} \mathrm{Sb}_{19} \mathrm{Se}_{85-x}$ glasses at heating rates of $1^{\circ} \mathrm{C} / \mathrm{min}$ and $5^{\circ} \mathrm{C} / \mathrm{min}$. The composition and temperature dependence of the thermal expansion coefficient is discussed in the light of results of other chalcogenide glasses.
\end{abstract}

Keywords. As-Sb-Se glasses; thermal expansion coefficient; glass transition region.

\section{Introduction}

The study of thermal expansion coefficient $(\alpha)$ of chalcogenide glasses has not received much attention as compared with other properties of these glasses. There are some data on the composition dependence of $\alpha$ for As-Se (Webber and Savage 1976), As-S (Tsuchihashi and Kawamoto 1970). Ge-As-Se (Webber and Savage 1976) and Ge-Sb-Se (Sudha Mahadevan et al 1984) glasses. There is a scatter of about $15 \%$ in the reported value of $\alpha$ for $\mathrm{As}_{2} \mathrm{~S}_{3}$ (Tsuchihashi and Kawamoto 1970; Hilton et al 1966) and of about $35 \%$ for $\mathrm{As}_{2} \mathrm{Se}_{3}$ (Henderson and Ast 1984; Webber and Savage 1976). It is generally known that the temperature dependence of $\alpha$ of glasses has two regions; an initial low temperature or 'normal' region where $\alpha$ is independent of temperature, followed by the glass transition region where $\alpha$ increases with increase of temperature. Measurement of $\alpha$ of Ge-Sb-Se glasses (Sudha Mahadevan et al 1984) using a conventional horizontal thermal dilatometer at a heating rate of $5^{\circ} \mathrm{C} / \mathrm{min}$ indicated that the increase of $\alpha$ with temperature in the transition region occurred over a temperature range of about $30^{\circ} \mathrm{C}$. This is followed by softening of the glasses. Values of $\alpha$ for $\mathrm{As}_{2} \mathrm{Se}_{3}$ measured using a parallel plate viscometer (Henderson and Ast 1984) indicate an abrupt increase of $\alpha$ (over a few degree temperature interval) from $15.5 \times 10^{-6} /{ }^{\circ} \mathrm{C}$ in the normal region to about $100 \times 10^{-6} /{ }^{\circ} \mathrm{C}$ after transition.

The results of measurement of $\alpha$ on eight glass compositions of the As-Sb-Se system are reported in this communication. The composition of four of these glasses can be represented by $(\mathrm{As}, \mathrm{Sb})_{40} \mathrm{Se}_{60}$. These fall along the $\mathrm{As}_{2} \mathrm{Se}_{3}-\mathrm{Sb}_{2} \mathrm{Se}_{3}$ psuedo-binary tie line and constitute the so-called 'stoichiometric' glasses of the As-Sb-Se system. The composition of the other four glasses studied can be represented by $\mathrm{As}_{x} \mathrm{Sb}_{15} \mathrm{Se}_{85}$; these four along with the stoichiometric composition with 15 atomic percent of $\mathrm{Sb}$, namely, $\mathrm{As}_{25} \mathrm{Sb}_{15} \mathrm{Se}_{60}$ form five glasses of the $\mathrm{As}_{x} \mathrm{Sb}_{15} \mathrm{Se}_{85-x}$ family of the As-Sb-Se system. The results of measurement of the glass transition temperature $\left(T_{g}\right)$, density, electrical conductivity and elastic properties of these glasses have been reported elsewhere (Giridhar and Sudha Mahadevan 1982; Giridhar et al 1984). 


\section{Experimental}

The elemental components ( $5 \mathrm{~N}$ purity, from Koch Light $\mathrm{Co}$ ) in appropriate atomic proportions (table 1) were sealed in quartz ampoules $(12 \mathrm{~mm}$ diameter) under a vacuum of $10^{-3}$ torr. The contents of the ampoule were melted in a rotary furnace at about $950^{\circ} \mathrm{C}$ for $24 \mathrm{hr}$. The charge was then cooled to $800^{\circ} \mathrm{C}$ and quenched in cold water to obtain glasses. Samples were cut into rectangular sections of $3 \mathrm{~mm}$ thick $\times 8 \mathrm{~mm}$ width and of length about $10 \mathrm{~mm}$ to $20 \mathrm{~mm}$ depending on the piece available in the glass preparation boule. The end faces normal to the length of the sample were rendered smooth and parallel using a hand polishing jig fabricated for this purpose. Before measurement each sample was annealed in situ by holding it for $30 \mathrm{~min}$ at a temperature of about $5^{\circ} \mathrm{C}$ higher than its $T_{g}$ and cooling it slowly.

The expansion measurements were made in a conventional horizontal dilatometer (thermal dilatometric analyser, Harrop Laboratories, USA, model TDA-H1-PP2) which was standardised against an alumina rod supplied with the instrument. The sample temperature was measured using a calibrated chromel-alumel thermocouple in contact with the sample. Using an X-Y recorder (sensitivity $0.2 \mathrm{mV} / \mathrm{cm}$., Watanabe model $W X 431$ ) in conjunction with the dilatometer, expansion of the samples were recorded from room temperature upto the respective softening temperature $\left(T_{s}\right)$ at heating rates of $5^{\circ} \mathrm{C} / \mathrm{min}$ and $1^{\circ} \mathrm{C} / \mathrm{min}$.

A typical trace showing the change in sample length $\Delta l_{s}$ versus temperature is shown in figure 1 for one of the compositions. Also shown in figure 1 is the corresponding $\alpha$ calculated using the expression $\alpha=\left(l / l_{s}\right)\left(\Delta l_{s} / \Delta T\right)$, with a temperature increment of $10^{\circ}$.

\section{Results and discussion}

\section{$3.1(A s, S b)_{40} S e_{60}$ glasses}

The results for these glasses are summarised in figures 2 and 3 and in table 1 . Three to four batches of glasses were prepared for each composition to assess the spread in the value of $\alpha$. While the samples from different batch preparations gave spread of about

Table 1. $T_{g}, \alpha$ and $\Delta \alpha$ data of As-Sb-Se glasses

\begin{tabular}{|c|c|c|c|c|c|}
\hline $\begin{array}{l}\text { Composition } \\
\text { As:Sb:Se }\end{array}$ & $\begin{array}{r}\boldsymbol{T}_{g}\left({ }^{\circ} \mathrm{C}\right. \\
1 \cdot 25^{\circ} \mathrm{C} \\
/ \mathrm{min}\end{array}$ & $\begin{array}{l}\mathrm{DSC} \\
5^{\circ} \mathrm{C} \\
/ \mathrm{min}\end{array}$ & $\begin{array}{c}\text { Range of } \alpha \text { (in the } \\
\text { normal region) } \\
\times 10^{6}\left(/{ }^{\circ} \mathrm{C}\right)\end{array}$ & $\Delta \alpha \times 10^{6}\left(/ /{ }^{\circ} \mathrm{C}\right)$ & $\begin{array}{c}V_{f} \times 10^{6} \\
\left(\simeq 3 \Delta \alpha T_{g}^{*}\right)\end{array}$ \\
\hline $10: 15: 75$ & 86 & 92 & $24 \cdot 0-25 \cdot 4$ & 65 & 0.072 \\
\hline $20: 15: 65$ & 135 & 142 & $21 \cdot 0-23 \cdot 0$ & 59 & 0.073 \\
\hline $30: 15: 55$ & 175.5 & 183 & $17.5-18.8$ & 55 & 0075 \\
\hline $35: 15: 50$ & $179 \cdot 5$ & 187.5 & $18.0-20.7$ & 50 & 0.069 \\
\hline $40: 0: 60$ & 164 & 171 & $19 \cdot 4-20.7$ & 70 & 0.093 \\
\hline $35: 5: 60$ & 167.5 & 175.5 & $18 \cdot 6-21.0$ & 53 & 0071 \\
\hline $30: 10: 60$ & 171.5 & 178.5 & $18 \cdot 3-20 \cdot 5$ & 60 & 0.081 \\
\hline $25: 15: 60$ & $174 \cdot 5$ & $181 \cdot 5$ & $17 \cdot 7-20 \cdot 0$ & 55 & 0.075 \\
\hline $22: 18: 60$ & 175 & 182 & $17 \cdot 2-19.0$ & 54 & 0.074 \\
\hline
\end{tabular}

* $T_{g}$ in ${ }^{\circ} \mathrm{K}$ has been used 


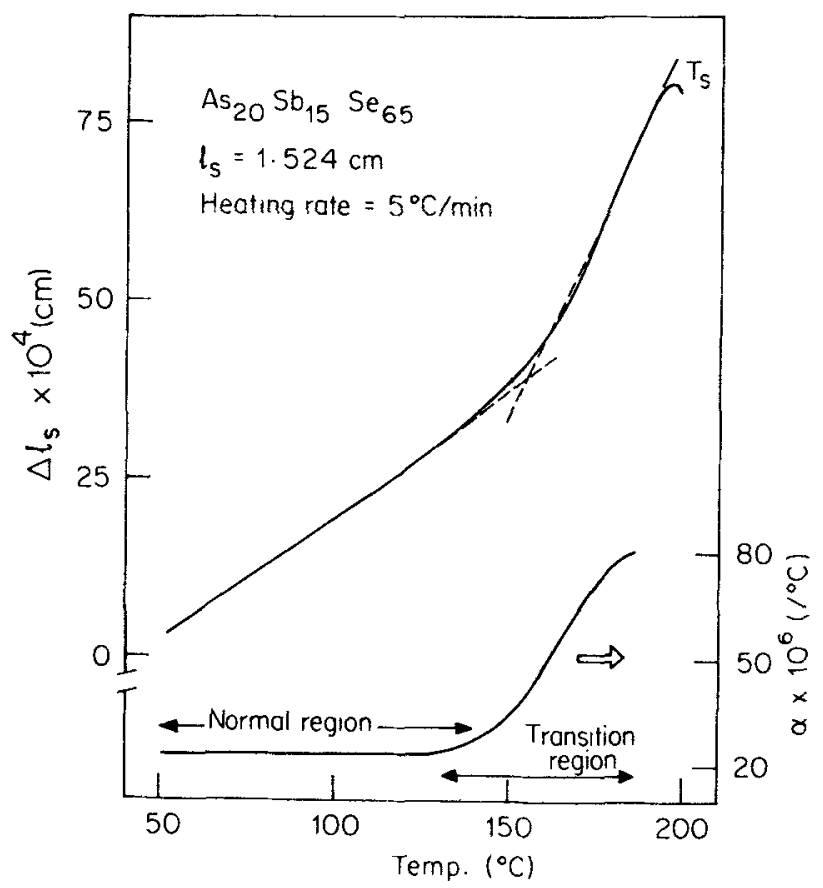

Figure 1. A typical data of the change in sample length $\Delta l_{s}$ versus temperature for one of the compositions. Also shown is the corresponding $\alpha$ obtained by $\alpha=\left(l / l_{s}\right)\left(\Delta l_{s} / \Delta T\right)$.

$6 \%$ to $12 \%$ depending on the composition, the value of $\alpha$ of samples from the same batch did not differ much. Because of the wide spread in the reported value of $\alpha$ for $\mathrm{As}_{2} \mathrm{Se}_{3}$, two batches of $\mathrm{As}_{40} \mathrm{Se}_{60}$ glass were prepared and $\alpha$ was measured for the present study. The results for this composition are also included in figures 2 and 3 . The $T_{g}$ 's of these glasses obtained at heating rates of $1.25^{\circ} \mathrm{C} / \mathrm{min}$ and $5^{\circ} \mathrm{C} / \mathrm{min}$ using a Perkin Elmer model DSC-2 differential scanning calorimeter are also included in table 1 . The temperatures at which $\alpha$ increases rapidly (figure 2 ) agree closely with $T_{g}$ 's of these glasses.

The variation of $\alpha$ in the transition region of these glasses at the slow heating rate $\left(1^{\circ} \mathrm{C} / \mathrm{min}\right.$, dotted line, figure 2$)$ indicates the existence of a relaxation process near $T_{g}$. It was found to be present in all the samples studied, though the magnitude of the effect differed. The origin of this relaxation process is not clear at present. It is probably similar to the relaxation process (Schnaus et al 1970) normally encountered in the measurement of heat capacity $\left(C_{p}\right)$ of glasses in the transition region. In heat capacity measurements it is attributed as an artifact of the rate dependence of glass properties in the transition region, and is associated with the structural relaxation times involved. However, further work is necessary to trace the origin of the relaxation process observed presently for these glasses.

The composition dependence of $\alpha$ of these glasses in the normal region is shown in figure 3 with the vertical bars indicating the range of $\alpha$ measured on samples from different batch preparations. A decrease of $\alpha$ with increase of Sb content in the glass is seen from the results of figure 3 . 


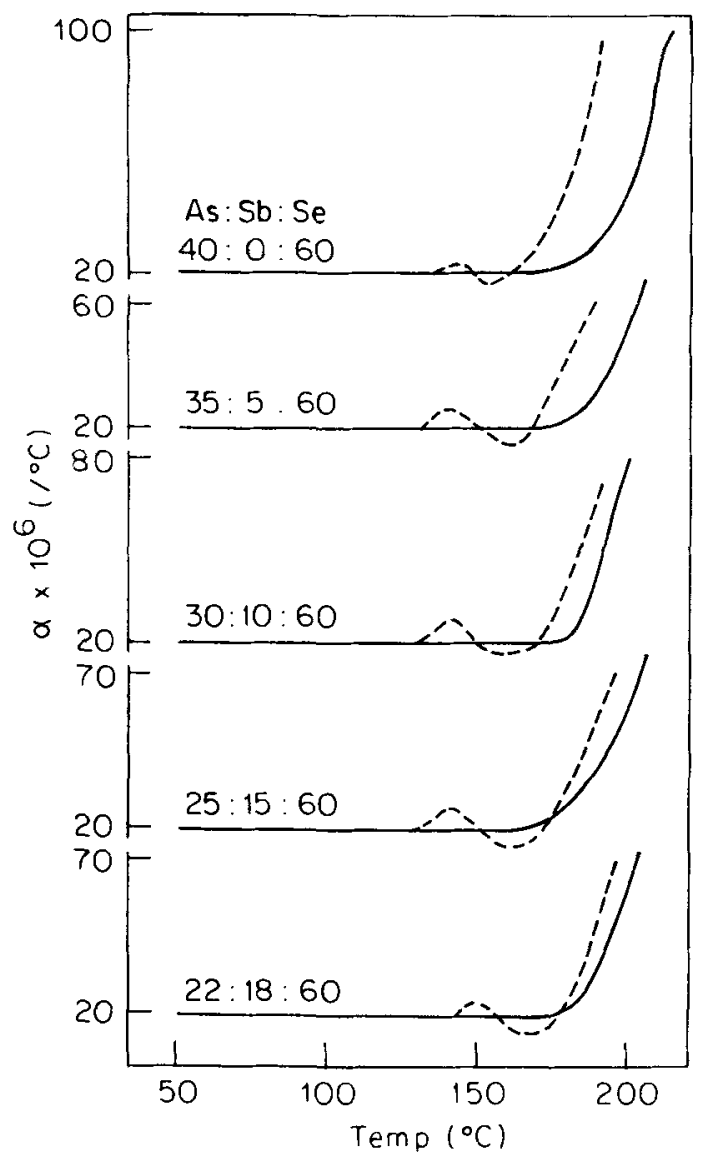

Figure 2. $\alpha-\mathrm{T}$ data for five glasses of $(\mathrm{As}, \mathrm{Sb})_{40} \mathrm{Se}_{60}$ (with $\mathrm{Sb}$ of $0,5,10,15$ and 18 atomic percent) at heating rates of $1^{\circ} \mathrm{C} / \mathrm{min}$ (broken lines) and $5^{\circ} \mathrm{C} / \mathrm{min}$ (continuous lines).

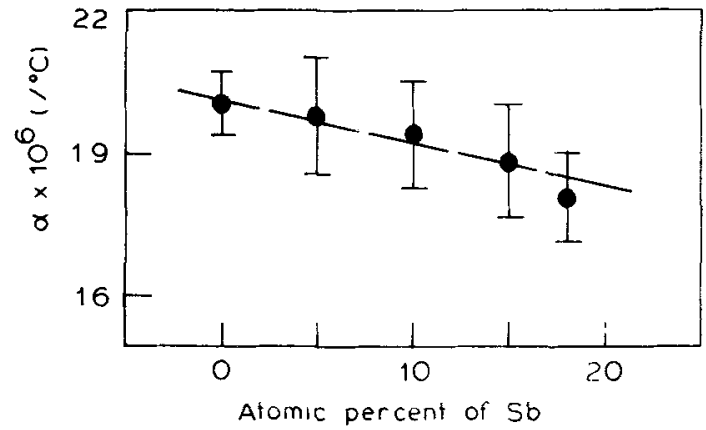

Figure 3. $\alpha$ in the normal region versus composition for (As, $\mathrm{Sb})_{40} \mathrm{Se}_{60}$ glasses. The vertical bars show the spread of $\alpha$ obtained by measurements on samples from different batch preparations. 


\section{$3.2 A s_{x} S b_{15} S_{85-x}$ glasses}

The variation of $\alpha$ with temperature for glasses of this family was similar to those shown in figure 2 for stoichiometric compositions, with $\alpha$ being constant upto the corresponding $T_{g}$, and increasing rapidly beyond that. However, the relaxation effect was not as prominent as in the case of stoichiometric glasses. The variation with composition of $\alpha$ in the normal region for these glasses is shown in figure 4 along with the $\alpha$-composition data of $\mathrm{As}_{x} \mathrm{Se}_{100-x}, \mathrm{Ge}_{x} \mathrm{As}_{10} \mathrm{Se}_{90-x}$ (Webber and Savage 1976), $\mathrm{Ge}_{x} \mathrm{Sb}_{15} \mathrm{Se}_{85-x}$ (Sudha Mahadevan et al 1984) and $\mathrm{As}_{x} \mathrm{~S}_{100-x}$ (Tsuchishshai and Kawamoto 1970) glasses. The lower values of $\alpha$ for the Ge rich glasses of the Ge-chalcogenide glasses (figure 4) can be understood on the basis that As-(S, Se) glasses are basically in the form of layers and chains while $\mathrm{Ge}-(\mathrm{S}, \mathrm{Se})$ glasses are generally in the form of threedimensional networks. In the composition dependence of $\alpha$ for Ge-Se (Feltz 1975), Ge$\mathrm{Sb}-\mathrm{Se}$ (figure 4) systems, a change of slope is seen at the respective stoichiometric composition, while for the As-S, As-Se systems (figure 4) a minimum is seen at the corresponding stoichiometric composition. A broad minimum is seen at the stoichiometric composition for the As-Sb-Se system. The variation in $\alpha$ with composition in $\mathrm{As}_{x} \mathrm{Sb}_{15} \mathrm{Se}_{85-x}$ is far less compared with those in case of $\mathrm{As}_{x} \mathrm{Se}_{100-x}$ and $\mathrm{As}_{x} \mathrm{~S}_{100-x}$

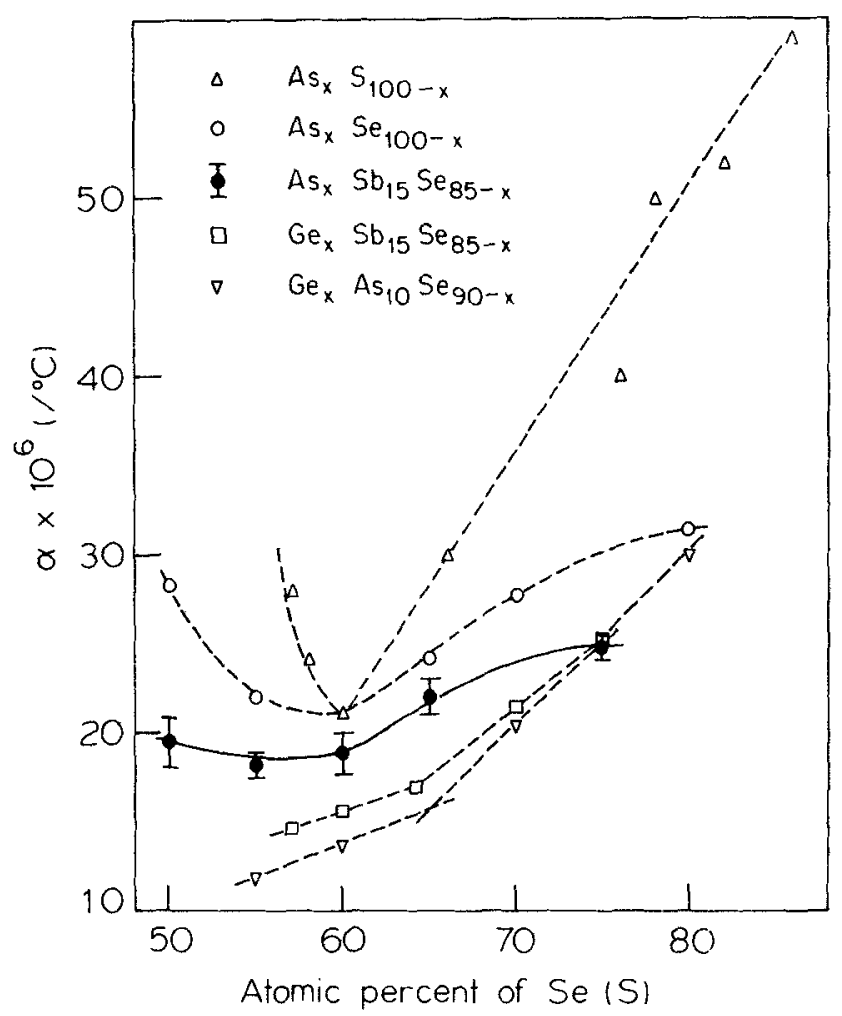

Figure 4. $\alpha$-composition data for $\mathrm{As}_{x} \mathrm{Sb}_{15} \mathrm{Se}_{85-x}$ glasses. Also shown in the graph are the $\alpha$ $T$ data from the literature for $\mathrm{As}_{x} \mathrm{~S}_{100-x}$ (Tsuchihashi and Kawamoto 1970). As $\mathrm{Se}_{\mathbf{x}} \mathrm{C}_{100-x}$ $\mathrm{Ge}_{x} \mathrm{As}_{10} \mathrm{Se}_{90-x}$ (Webber and Savage 1976) and $\mathrm{Ge}_{x} \mathrm{Sb}_{15} \mathrm{Se}_{85-x}$ (Sudha Mahadevan et al 1984) glasses. 
(figure 4) glasses. The addition of $\mathrm{Sb}$ seems to suppress the variation of $\alpha$ with composition.

\subsection{Variation of $\alpha$ in the transition region}

In the normal region, the $\alpha$ of these glasses is not dependent on the temperature or the heating rate employed for the measurement. In the transition region, a marked dependence of $\alpha$ is seen both on the temperature and on the heating rate. This behaviour is similar to the behaviour of heat capacity of glasses in the transition region (Schnaus et al 1973). The region of rapidly increasing $\alpha$ is shifted to higher temperature as the heating rate is increased (figure 2), a behaviour similar to that of the heat capacity of glasses.

These measurements, as many others made earlier, indicate that $\alpha$ increases in the transition region. The present measurements have been made with a dilatometer wherein a probe rod under load makes contact with the sample. The temperature in the set-up has been varied continuously at a chosen heating rate. The results for $\mathrm{As}_{2} \mathrm{Se}_{3}$ at heating rates of $1^{\circ} \mathrm{C} / \mathrm{min}$ and $5^{\circ} \mathrm{C} / \mathrm{min}$ are shown in figure 5 (traces a and b respectively). In these cases, $\alpha$ has been calculated from the slope of the $\Delta l_{s}$ versus $T$ trace (similar to that of figure 1) with a $10^{\circ} \mathrm{C}$ temperature increment. The increase in $\alpha$ is spread over a temperature of about $45^{\circ} \mathrm{C}$ for $5^{\circ} \mathrm{C} / \mathrm{min}$ heating rate, and about $30^{\circ} \mathrm{C}$ for $1.25^{\circ} \mathrm{C} / \mathrm{min}$ heating rate. It is interesting to note in this context that the expansion data of $\mathrm{As}_{2} \mathrm{Se}_{3}$ and $\mathrm{As}_{2} \mathrm{~S}_{3}-\mathrm{PbS}$ glasses (Bhat and Bhatia 1978) also indicate an increase in $\alpha$ taking place over a temperature range of about $40^{\circ} \mathrm{C}$ in the transition region. Recent results (Ahmed et al 1985) on thermal expansion of mixed alkali borate glasses also indicate an increase in $\alpha$ occurring over a temperature interval of more than $75^{\circ} \mathrm{C}$ around the transition region for some of the compositions. This is to be expected because the transformation to a glass does not take place at one strictly defined temperature, but within a temperature range, representing the transformation region (Maurer 1968; Vacher et al 1974; Rehage and Borchard 1973). However, it is a general

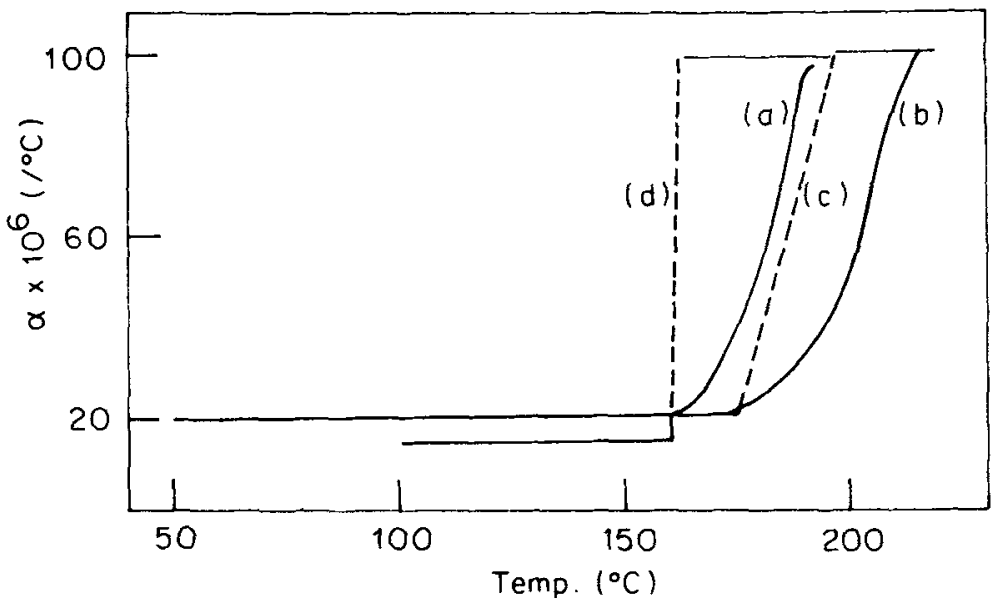

Figure 5. $\alpha-T$ in the transition region for $\mathrm{As}_{2} \mathrm{Se}_{3}$ at the heating rates of $1^{\circ} \mathrm{C} / \mathrm{min}$ (trace a) and $5^{\circ} \mathrm{C} / \mathrm{min}$ (trace b). Trace $\mathrm{c}$ is calculated from the data obtained at the heating rate of $5^{\circ} \mathrm{C} / \mathrm{min}$ by approximating the $\Delta l_{s}$ vs $T$ in the transition region to a straight line. The data of Henderson and Ast (1984) obtained from viscometer measurement is shown in trace d. 
practice to approximate the variation of $\Delta l_{s}$ with $T$ in the transition region to a straight line (as shown by the dotted line in figure 1) and ascribe a value for $\alpha$ after transition as inferred from the slope of this line. The result of such a calculation (for the heating rate of $5^{\circ} \mathrm{C} / \mathrm{min}$ ) for $\mathrm{As}_{2} \mathrm{Se}_{3}$ is as shown in trace (c) of figure 5. Also shown in figure 5 are the data on $\alpha$ of $\mathrm{As}_{2} \mathrm{Se}_{3}$ obtained by Henderson and Ast (1984) (trace (d), figure 5). The maximum value of $\alpha$ of about $100 \times 10^{-6} /{ }^{\circ} \mathrm{C}$ obtained presently agrees well with that obtained by Henderson and Ast (1984). However, the manner in which $\alpha$ increases in the transition region before reaching its maximum value is different in the two measurements. In the set-up used by Henderson and Ast, the sample is placed between the plates of a parallel plate viscometer and the temperature is increased in steps. In this sense, these measurements are under isothermal conditions. Henderson and Ast (1984) also reported that the load used did not cause any deformation of the sample. The $\alpha$ in this case is seen to increase to its final value in a few degrees range of temperature, whereas the present measurements indicate that the increase is spread over a wider range of temperature. This feature is introduced because of the continuous heating. The increase in $\alpha$ is spread over a range of $45^{\circ} \mathrm{C}$ for $5^{\circ} \mathrm{C} / \mathrm{min}$ heating rate and about $30^{\circ} \mathrm{C}$ for the $1.25^{\circ} \mathrm{C} / \mathrm{min}$ heating rate. Also, by approximating the $\Delta l_{s}$ vs $T$ in the transition to a straight line, the spread of temperature range over which the increase in $\alpha$ occurs is narrowed down, as can be seen from trace (c) of figure 5. It is to be expected that at still slower heating rates (approaching isothermal conditions) the spread will further decrease and resemble the data of Henderson and Ast (1984). Isothermal measurements were attempted on the dilatometer to check this point. But this could not be checked because the probe rod started indenting the sample when the sample was held for a sufficiently long time at any temperature in the transition region, indicating an apparent decrease in length. Thus while there is an increase of $\alpha$ in the transition region, the detailed nature of this increase seems to depend on the heating rate employed, the procedure used to evaluate $\alpha$ (from the $\Delta l_{s}$ vs $T$ data) and the method employed for the measurement of $\alpha$.

The free volume $V_{f}$ during glass transition is given (Simha and Boyer 1962; Suzuki et al 1971) as the product of the difference in cubical expansion coefficient above and below the glass transition temperature and $T_{g} \cdot V_{f}$ is of the order of $3 \Delta \alpha T_{g}$ where $\Delta \alpha$ is the change in linear expansion coefficient above and below $T_{g}$. For oxide glasses, the ratio of free volumes, namely, $V_{f\left(\mathrm{~B}_{2} \mathrm{O}_{3}\right)} / V_{f\left(\mathrm{GeO}_{2}\right)}$ is found to be equal to eight, while by considering the average free volume changes in As-Se, As-S, Ge-Se and Ge-S systems, it has been found that $V_{f\left(\mathrm{As}_{2} \mathrm{Se}_{3}\right)} / V_{f\left(\mathrm{GeSe}_{2}\right)}$ is about 1.2 and $V_{f\left(A s_{2} \mathrm{~S}_{3}\right)} / V_{f\left(\mathrm{GeS}_{2}\right)}$ is about 1 (Suzuki and Abe 1981). It is therefore concluded (Suzuki and Abe 1981; Suzuki et al 1978) that chalcogenide glasses are in a state of isofree volume during glass transition. The average value of $V_{f}$ for $\left(\mathrm{As}_{2} \mathrm{Se}_{3}\right)\left(\mathrm{Sb}_{2} \mathrm{Se}_{3}\right)$ glasses (table 1) is seen to be 0.0789. The average value of $V_{f}$ from the data of $\Delta \alpha$ and $T_{g}$ for $\left(\mathrm{GeSe}_{2}\right)\left(\mathrm{Sb}_{2} \mathrm{Se}_{3}\right)$ glasses (Sudha Mahadevan et al 1984) is seen to be 0.0760 . The value of 1.04 for the ratio $V_{f\left(\mathrm{As}_{2} \mathrm{Se}_{3}\right)\left(\mathrm{Sb}_{2} \mathrm{Se}_{3}\right)} / V_{f\left(\mathrm{GeSe}_{2}\right)\left(\mathrm{Sb}_{2} \mathrm{Se}_{3}\right)}$ therefore falls in line with the general observation of isofree volume during glass transition for chalcogenide glasses, despite the difference in structure.

\section{Summary and conclusions}

Measurements have been made on the dependence of thermal expansion coefficient $(\alpha)$ on temperature and composition for eight glass compositions of the As-Sb-Se system at 
the heating rates of $1^{\circ} \mathrm{C} / \mathrm{min}$ and $5^{\circ} \mathrm{C} / \mathrm{min}$. The $\alpha$-T data indicate an initial 'normal' region where $\alpha$ is independent of temperature followed by a 'transition' region where $\alpha$ increases steeply with temperature. The temperature where $\alpha$ begins to show a steep increase shifts to higher values as the heating rate is increased. The detailed nature of the increase of $\alpha$ in the transition region seems to depend on the heating rate employed, the procedure used to evaluate $\alpha$ and the method employed for the measurement of $\alpha$.

The composition dependence of $\alpha$ of $\mathrm{As}_{x} \mathrm{Sb}_{15} \mathrm{Se}_{85}-x$ glasses have been compared with those of $\mathrm{As}_{x} \mathrm{~S}_{100-x}$ and $\mathrm{As}_{x} \mathrm{Se}_{100-x}$ glasses. A broad minimum is seen at the 'stoichiometric' composition $\mathrm{As}_{25} \mathrm{Sb}_{15} \mathrm{Se}_{60}$ in the $\alpha$-composition dependence of these glasses.

The $\alpha$ in the 'normal' region for $(\mathrm{As}, \mathrm{Sb})_{40} \mathrm{Se}_{60}$ glasses shows a slight decrease with increasing Sb content in the glasses. At the heating rate of $1^{\circ} \mathrm{C} / \mathrm{min}$, these glasses exhibit a relaxation process around the transition region. The results on $\alpha$ and $T_{g}$ of these glasses along with those of Ge-Sb-Se glasses fall in line with the general observation of iso-free volume during glass transition for chalcogenide glasses, despite differences in structure.

\section{References}

Ahmed A A, Abbas A F and Salman S M 1985 Phys. Chem. Glasses 2617

Bhat P K and Bhatia K L 1978 Phys. Chem. Glasses 1955

Feltz A 1975 Z. Anorg. Allg. Chem. 41220

Giridhar A and Sudha Mahadevan 1982 J. Non-Cryst. Solids 51305

Giridhar A, Sudha Mahadevan and Singh A K 1984 Bull. Mater. Sci. 61001

Henderson W and Ast D G 1984 J. Non-Cryst. Solids 6443

Hilton A R, Jones C E and Brau M 1966 Phys. Chem. Glasses 7105

Kawamoto Y and Tsuchihashi S 1971 J. Am. Cer. Soc. 54131

Maurer J J 1968 in Analytical chemistry VI (New York: Plenum Press) pp 107

Rehage C and Borchard W 1973 in The physics of glassy polymers (London: Applied Science Publications) pp 54

Schnaus V E, Moynihan C T, Gammon R W and Macedo P B 1970 Phys. Chem. Glasses 11213

Simha R and Boyer R F 1962 J. Chem. Phys. 371003

Sudha Mahadevan, Giridhar A, Narasimham P S L and Singh A K 1984 J. Non-Cryst. Solids 65233

Suzuki S and Abe Y 1981 J. Non-Cryst. Solids 43141

Suzuki S, Takahashi M and Kobayoshi T 1978 Yogyo Kyokai Shi 86428

Tsuchihashi S and Kawamoto S 1970 J. Non-Cryst. Solids 5286

Vacher R, Delsanti M, Pelous J, Cechi L, Winter A and Zarzyki J 1984 J. Mater. Sci. 9829

Webber P J and Savage J A 1976 J. Non-Cryst. Solids 20271 